\title{
Trauma, posttraumatic stress disorder and psychosis: Etiopathogenic and nosological implications
}

\author{
Álvaro Frías Ibáñez $z^{*, * *}$ \\ Carolina Palma Sevillano** \\ Eloi Giné Serven* \\ Elena Aluco Sánchez* \\ ${ }^{*}$ Psychiatry Unit. Hospital of Mataró \\ ** FPCEE Blanquerna. Ramon Llull \\ University \\ SPAIN
}

\begin{abstract}
Background and Objectives: The relationship between trauma, post-traumatic stress disorder (PTSD), and psychosis has promoted heterogeneous research lines, in both etiopathogenic and nosological areas. The main aim of this review is to provide a systematic framework that encompasses this theoretical gap in the literature.

Methods: A literature research was carried out through PubMed and PsycINFO between 1980 and May 2013. One hundred and thirteen articles were recruited. A first part of this review describes the role of trauma in the development of psychosis. The second part focuses on research about PTSD and psychosis.

Results: Longitudinal and cross-sectional studies with clinical and community samples confirm that childhood trauma (CT) is a vulnerability factor for schizophrenia and psychotic-like symptoms in adulthood. More empirical research is needed in order to assess the role of trauma as precipitant of acute psychosis. There is also preliminary evidence with cross-sectional samples that suggests that PTSD and psychosis are a risk factor for each other, with studies about post-psychotic PTSD (PP-PTSD) being outstanding. Finally, results from different comparative research studies postulate a subtype of PTSD with psychotic features (PTSD-SP).

Conclusions: The role of trauma in psychosis is more conclusive as predispositional rather than as trigger factor. Nosological status of acute psychoses remains a focus of controversy unresolved. The association between PTSD and psychosis is complex, requiring more prospective research in order to determine causal relationships between these pathologies. Also, research in nosological status of PTSD-SP must encourage more comparative studies not limited to neurobiological variables.
\end{abstract}

Received: 2 July 2013

Revised: 7 November 2013

Accepted: 12 November 2013 


\section{Introduction}

The presence of trauma and post-traumatic stress disorder (PTSD) in subjects with psychotic symptoms has produced a considerable amount of research, both heterogeneous and unconnected in terms of approaches and areas of development, mainly conditioned by the prevailing psychiatric paradigm in every historical period. In this sense, literature specialised in this topic has promoted different etiopathogenic and nosological models in this issue.

Over the two first thirds of twentieth century, research in this issue was solely focused in the role of trauma as a trigger factor for acute psychoses, traditionally called hysterical psychosis (HP) or psychogenic psychosis $(\mathrm{PP})^{1}$. However, in the last decade other research lines have been promoted alien to traditional assumptions, with an inclusion of theoretical-clinical aspects not considered before. On the one hand, from an etiopathogenic perspective, many empirical studies have been carried out in relation to the role of childhood trauma (CT) as a predispositional factor for schizophrenia or psychotic-like symptoms in adulthood ${ }^{2}$. On the other hand, concerning the relationship between PTSD and psychosis, the existence of a subgroup of subjects with PTSD with secondary psychotic features (PTSD-SP) has been considered $^{3}$, as well as other patients with postpsychotic PTSD (PP-PTSD) ${ }^{4}$.

\section{Objectives and method}

In this general framework, this theoretical review has the main aim of offering a systematic analysis of the main research lines and empiric evidence available about trauma and
PTSD in subjects with psychosis. With this purpose, a literature research was carried out through PubMed and PsycINFO between 1980 and May 2013. The descriptors used were "hysterical psychosis", "psychogenic psychosis", "post-traumatic psychosis", "reactive psychosis", "trauma", "childhood trauma", "psychosis", "schizophrenia" and "post-traumatic stress disorder". One hundred and thirteen articles were recruited, including theoretical, quasi-experimental, and descriptive studies. Studies that included adolescent patients were excluded because of exceeding the scope and main goals of this review. Findings were grouped into two thematic blocks. A first part describes the role of trauma in the development of psychosis, whether as 1) predisposing factor for schizophrenia or positive symptoms in adulthood, or as 2) triggering variable for acute psychosis. On the other hand, the second part focuses on research about PTSD and psychosis, with results being regrouped by considering 1) prevalence data, 2) theories explaining this relationship, and finally 3) nosological status of PTSD-SP.

\section{Role of trauma in the etiopathogenesis of psychoses}

\section{- CT as predisposing factor for schizophrenia or positive symptoms in adulthood}

With regard to the role of CT as a vulnerability factor for psychosis, many cross-sectional and prospective studies agreed in considering that the risk of having schizophrenia or positive symptoms (psychotic-like symptoms) in adulthood is over two-fold to fourfold if the subject has been the victim of some traumatic event in both childhood and adolescence periods ${ }^{5,6}$. These findings emerged in research studies with 1) clinical samples of chronic psychotic patients, "first episodes" 
and ultra-high-risk (UHR) for psychosis ${ }^{7-12}$, 2) general adult population ${ }^{13,14}$, and 3) cohorts of women that had been sexually assaulted $^{15}$. At a comparative level, no more history of CT was found in patients with psychosis when the control group were subjects with another psychiatric pathology (e.g., major depression $)^{2}$. From a dimensional perspective, different community studies obtained a specific association between $\mathrm{CT}$ and presence of hallucinations in adulthood ${ }^{16-21}$, particularly if the traumatic events involved sexual abuse $22-24$.

Additionally, different variables were proposed as possible modifiers in the relationship between CT and psychosis: characteristics of the trauma (frequency and nature), genetic predisposition, gender, and cannabis abuse. As for the traumatic event, many research studies with clinical and community samples claimed that the relationship between these two variables is "dose-dependent", that is, the relative risk of having a psychosis increases as the frequency of traumatic events is higher in childhood ${ }^{25-31}$. Concerning the nature of the traumatic event, there is no consistent data to confirm a higher risk of having psychosis among people that have been victims of a specific type of $\mathrm{CT}^{6}$. In this sense, many research studies with community or UHR for psychosis population observed that the relative risk increases in those subjects that had been victims of either sexual abuse $e^{7,11}$ or physical abuse $\mathrm{e}^{29,32,33}$. With regard to biological predisposition, a study with a sample of twins observed that the probability of having psychotic-like symptoms connected to CT is modulated by a genetic predisposition for depression ${ }^{34}$. As for the subjects' gender, a research study with a community sample with control group found higher CT frequency in women (versus men) with first psychotic episodes ${ }^{33}$. Finally, concerning substance abuse, there is agreement in point- ing that people with childhood trauma events are at higher risk for psychosis in adulthood if they use cannabis in their early and/or mid adolescence ${ }^{6,35,36}$.

With regard to variables mediating the association between CT and psychosis, different explanatory factors have been proposed: dysfunctional cognitive schemas, dissociative mechanisms, high levels of anxiety, and traumagenic neurodevelopment. From cognitive-behavioural models, many studies with community samples found that the presence of a history of CT contributes to the development of negative cognitive schemas about the Self and the others, which predispose to psychotic-like symptoms in adulthood, mainly paranoid delusions ${ }^{15,26,28,37,38}$. On the other hand, a series of research studies with samples of psychotic patients claimed that the presence of dissociative processes following CT accounts for the emergence of psychoticlike symptoms in adulthood, particularly hallucinations ${ }^{15,23,39-41}$, Likewise, other studies with clinical and community samples considered that high anxiety partially results in psychotic-like symptoms in subjects with traumatic events in their childhood or adolescence phases $22,42-44$. Finally, from a biological perspective, a "traumagenic neurodevelopmental model" was proposed, which states that the stress created by CT would cause early impairments in the hypothalamicpituitary-adrenal (HPA) axis and dopamine regulation, increasing the possibility of having a psychosis ${ }^{45-47}$. Additionally, a crosssectional research with neuroimaging highlighted a positive relationship between CT and hippocampal and amygdalar volumes in a sample of first psychotic episodes ${ }^{48}$.

In sum, childhood traumatic events are an unspecific risk factor for psychosis in adulthood, particularly hallucinations. Cannabis abuse and accumulation of traumas increase this probability. At a dimensional level, the 
development of negative cognitive schemas and dissociative processes has been associated to the presence of paranoid delusions and hallucinations, respectively.

\section{- Trauma as a triggering factor for acute psychosis}

With regard to the role of trauma as triggering acute psychosis, there are scarce empirical studies that have assessed this issue in the last fifteen years. Over this period, most of these studies have focused in elucidating the general role of life events rather than traumatic ones as a trigger factor for psychosis. Concerning to this topic, there are preliminary evidences suggesting that psychotic patients have a 3 -fold greater risk of life events prior to their onset compared with control groups $^{49}$. Likewise, amongst the few studies aimed to establish the specific role of trauma in the outset of acute psychosis not classified as schizophrenia, one study found that the presence of a intrusive event (e.g., physical assault) was more likely to be associated with an increased risk of psychosis, most commonly in the 3 months pre-onset (34\% cases vs $3 \%$ controls $)^{50}$.

Overall, this current deficit of studies is due to a lack of agreement in relation to the nosological status of acute psychoses triggered by serious stressors, a fact that is reflected in the relevance given to these clinical entities in current psychiatric nosology. On the one hand, the ICD- $10^{51}$ describes a series of "acute and transient psychotic disorders", which can be or not secondary to stressful situations. As for the DSM-IV-TR ${ }^{52}$, it recognises the existence of the "brief psychotic disorder", which may be preceded or not by a severe triggering factor, with its presence being equivalent to the "brief reactive psychosis" already defined in the DSMIII-TR ${ }^{53}$. Both manuals classify this kind of psychotic conditions in the same cluster that other acute psychoses of a more endogenous nature (e.g., cycloid psychosis), focusing on time or evolutionary criteria for their grouping. This explains that research studies carried out in the last two decades have been mainly aimed at distinguishing this heterogeneous group of acute psychoses from schizophrenia ${ }^{54-56}$.

In contrast to this current nosological framework, there is some historical background that illustrates and delimits these psychotic disorders triggered by trauma. On the one hand, French psychiatry coined the term $\mathrm{HP}^{57}$ in the second half of the nineteenth century, with this pathology being conceptualized as a dissociative phenomenon ${ }^{58}$. On the other hand, the Scandinavian school developed, in the first third of the twentieth century, a similar concept called PP ${ }^{1}$. Both approaches converged when observing that this kind of psychotic disorder has 1) an abrupt onset after a traumatizing event, 2) a self-limited duration of a few weeks, 3) positive symptomatology, 4) mood lability, and 5) recovery ad integrum $^{59-61}$. Despite this remarkable clinical agreement, both nosological constructs fell into disuse in the decades following their formulation. With regard to HP, many patients were diagnosed with schizophrenia once this term had been introduced in psychiatric nosology. Concerning PP, its dissemination was limited from the very beginning due to the use of a minority language $\mathrm{e}^{62,63}$. In the case of HP, some authors tried to apply this construct later ${ }^{64}$, with no conclusive data about its nosological validity, particularly concerning its brief or transient nature 65-68. $^{65}$.

In summary, current psychiatric nosology recognises post-traumatic psychoses in a residual manner. Despite having relative clinical validity ${ }^{69}$, there is no agreement when defining their distinctive characteristics from an empirical perspective. 


\section{PTSD and psychosis in traumatized subjects}

\section{- Prevalence}

With regard to prevalence data between PTSD and psychosis, two types of studies have been carried out. On the one hand, research studies with psychotic patients aimed at determining comorbidity with PTSD. On the other hand, studies in subjects with PTSD, which assessed the presence of psychoticlike symptoms associated with this condition, a clinical phenotype called PTSD-SP ${ }^{70}$.

As for the comorbidity between PTSD and schizophrenia, prevalence data are in a range between $11 \%$ and $53 \%{ }^{71-74}$. These findings in samples of psychotic patients are significantly higher to the percentage of subjects with PTSD in general adult population, with an estimated range from $3 \%$ to $5 \%$. With regard to the prevalence of PTSD-SP, available data in samples of former combatants show that $17-20 \%$ of these subjects with PTSD have secondary positive symptoms associated with trauma (e.g., paranoid delusions) ${ }^{76-78}$. Two factors have been pointed as responsible for possibly overestimating this association. On the one hand, comorbid mental disorders that would really account for the presence of psychotic-like symptoms in PTSD samples (e.g., psychotic depression). On the other hand, potential biases when distinguishing re-experiencing symptoms (e.g., intrusive images) from psychotic ones (e.g., visual hallucinations). As for the first issue, a study that excluded those patients with major depression reduced PTSD-SP prevalence in $2.5 \%$ in samples of traumatized patients ${ }^{76}$.

In sum, there are epidemiological findings in clinical samples suggesting that the association between PTSD and psychosis happens with higher probability than in general population.

\section{- Theories explaining the association between PTSD and psychosis}

From these results on prevalence, different hypotheses have been proposed as possible etiopathogenic mechanisms of the relationship between PTSD and psychosis (schizophrenia or psychotic-like symptoms). On the one hand, one of the two disorders would emerge as predisposing for the other (unidirectional theory). On the other hand, third variables would justify this co-occurrence (theory of common risk factors).

With regard to the first approach, there is empirical evidence to claim that both pathologies are a vulnerability variable for the other disorder. In the case of subjects with PTSD, different cross-sectional research studies with community samples showed that the risk of having psychotic-like symptoms is at least twice as higher as the one observed in general population (odds ratio $=1.8-3.5$ ), with a higher predisposition to delusional symptomatology being outstanding $28,38,76,79,80$. Concerning this hypothesis, a model of continuity between PTSD and psychosis has been proposed, in such a way that the psychotic condition would indeed be an exacerbation of the former condition ${ }^{79,81}$.

On the other hand, within this unidirectional theory, a series of mainly cross-sectional studies have aimed at determining the risk of having PTSD as a result of psychosis onset, a fact called PP-PTSD ${ }^{4}$. On this issue, many studies with clinical samples of subjects with first psychotic episodes showed that the prevalence of PTSD ranges from $11 \%$ to $67 \%$, being diagnosed in a third of patients assessed on average $e^{4,82-88}$. Two variables have been identified as potential precursors of this post-traumatic condition: positive symptoms and the type of psychiatric admission (e.g., voluntary vs. involuntary). Concerning the first factor, there are partially 
consistent findings to establish a positive relationship between presence or severity of positive symptoms and $\mathrm{PTSD}^{82,85,87,88}$. As for the kind of admission and/or treatment, the association is less conclusive ${ }^{82,84,85,87}$. Together, these data have posed the question of what variables could be modulating the relationship between these variables and PTSD. In this sense, current findings suggest that the presence of PTSD in subjects with first psychotic episodes is higher if 1) they have a previous history of trauma, 2) use dysfunctional assessment and coping strategies in front of stress (e.g., experience of uncontrollability), and 3) show comorbid depressive symptoms $4,82-84,88-90$.

Finally, regarding the existence of common factors in PTSD and psychosis, only two proposals have been carried out from divergent approaches. On the one hand, a "model of cognitive integration" has been proposed, which considers that both disorders would be pathologies in the post-traumatic spectrum with similar explanatory mechanisms at the level of cognitive schemas, attributional styles and dissociative processes ${ }^{91}$. On the other hand, from a neurobiological perspective, it is considered that both disorders imply a dysfunction in the HPA axis, thus causing a dysregulation in the release of cortisol in response to stress ${ }^{45}$.

In summary, there is empirical evidence to suggest a possible reciprocal influence between both types of psychopathology. As for the presence of third variables, there is scarce research comparing PTSD and schizophrenia to determine this approach.

\section{- Nosological status of PTSD-SP}

The high prevalence of subjects with PTSD and co-occurring positive symptoms has encouraged a last line of research aimed at determining the nosological status of those patients with PTSD-SP $3,92,93$.
At a methodological level, most of these research studies have been conducted with war veteran samples diagnosed with PTSD "with" versus "without" psychotic-like symptoms, with different neurobiological markers being used as dependent variables. The main results of these studies show that subjects with PTSD-SP have 1) a higher concentration of platelet serotonin, 2) higher levels of corticotropin-releasing factor in the cerebrospinal fluid, 3) a higher concentration of plasma dopamine beta-hydroxylase, 4) specific deficits in smooth pursuit eye movement, and 5) a higher presence of Met alleles in the BDNF Val66Met polymorphism ${ }^{94-98}$. Likewise, different open clinical trials found that the administration of neuroleptics as a monotherapy for 6-8 weeks reduces symptoms in those subjects with PTSD-SP resistant to conventional antidepressant treatment ${ }^{99-101}$. On the other hand, at a psychopathological level, subjects with PTSD-SP have a more severe posttraumatic condition ${ }^{80}$. Finally, from statistical techniques such as latent class analysis, evidence has been found in favour of this nosological approach ${ }^{102}$.

In summary, there is preliminary evidence, particularly at a neurobiological level, to advocate a subtype of PTSD-SP103,104.

\section{Discussion and conclusions}

\section{- Summary}

In this theoretical review, we have presented the main findings and research studies about trauma and PTSD in subjects with psychosis. With regard to the role of CT, there is conclusive evidence about its influence as an unspecific risk factor, both for schizophrenia and positive symptoms (psychoticlike symptoms) in adulthood. Concerning the relevance of trauma as a triggering factor of 
acute psychotic conditions, there is scarce empirical research that assesses this etiopathogenic approach, with these psychoses being residually integrated into current psychiatric nosology. On the other hand, concerning the theories explaining the relationship between PTSD and psychosis (schizophrenia or positive symptoms), there is preliminary evidence to establish a two-directional causality between both pathologies. Finally, consistent results have been obtained that would confirm a subtype of PTSD-SP.

\section{- Methodological limitations}

With regard to the limitations of studies on trauma and psychosis, there is a lack of empirical research aimed at clarifying the nosological status and clinical characteristics of acute psychoses triggered by a trauma or serious stressor, particularly in view of distinguishing them from other more endogenous acute psychoses. In this sense, studies that determine the role of trauma in the pathoplasty of psychosis have to be encouraged, particularly in relation to the content of delusions or hallucinations. In this issue, there are some research studies that show a relationship between history of sexual abuse and nature of psychotic symptoms ${ }^{24,105,106}$. As for the theories explaining the association between PTSD and psychosis, prospective research has to be promoted to reliably determine the relationships of causality between both types of psychopathology. Likewise, there are scarce studies comparing PTSD versus psychosis with the aim of assessing potential common factors at the neurobiological, neuropsychological and/or cognitive level. With regard to the nosological status of PTSD-SP, more comparative research studies have to be encouraged to determine this question, with the inclusion of other external criteria apart from neurobiological variables (e.g., degree of psychosocial dysfunctionality, neurocognitive profile). Likewise, controlled clinical trials have to be conducted with long-term follow-up in order to assess the efficiency of neuroleptics in this subgroup of patients. Finally, there are not comparative studies regarding clinical and functional differences between PP-PTSD and PTSD-SP. Thus, further research is warranted in this last issue.

\section{- Clinical implications}

- In the field of primary prevention, it is required to develop psychotherapy in those subjects with CT and UHR for psychosis, thus focusing the intervention on negative cognitive schemas and dissociative mechanisms involved.

- At a nosological level, false positive diagnosis of chronic psychosis has to be avoided in those subjects that develop psychotic experiences after a serious stressful event. It is necessary to assess the evolutionary course in order to carry out the appropriate differential diagnosis.

- In subjects with a primary diagnosis of schizophrenia, the possible occurrence of PTSD has to be assessed and treated with conventional psychotherapy ${ }^{107-111}$, especially considering that co-morbidity is an indicator of higher suicidal risk ${ }^{71,74}$. Specifically, the potential post-traumatic symptoms in subjects with first psychotic episodes (PP-PTSD) has to be assessed, with the optimization of coping strategies in front of stress and the integration of the psychotic experience being a priority in these cases ${ }^{85,86,112,113}$.

- In subjects with a primary diagnosis of PTSD, it is necessary to assess associated psychotic-like symptoms (PTSD-SP), in which case treatment with neuroleptics should be implemented. 


\section{References}

1. Schioldann J. Psychogenic psychoses by August Wimmer (1936): Part 1. Hist Psychiatry 2011; 22: 344-357.

2. Bendall S, Jackson HJ, Hulbert CA, McGorry PD. Childhood trauma and psychotic disorders: a systematic, critical review of the evidence. Schizophr Bull 2008; 34: 568-579.

3. Lindley SE, Carlson E, Sheikh J. Psychotic symptoms in posttraumatic stress disorder. CNS Spectr 2000; 5: 52-57.

4. Brunet K, Birchwood M, Upthegrove R, Michail M, Ross K. A prospective study of PTSD following recovery from first-episode psychosis: the threat from persecutors, voices, and patienthood. Br J Clin Psychol 2012; 51: 418-433.

5. van Winkel R, van Nierop M, Myin-Germeys I, van Os J. Childhood trauma as a cause of psychosis: linking genes, psychology, and biology. Can J Psychiatry 2013; 58: 44-51.

6. Varese F, Smeets F, Drukker M, Lieverse R, Lataster $\mathrm{T}$, Viechtbauer W, et al. Childhood adversities increase the risk of psychosis: a meta-analysis of patient-control, prospective- and cross-sectional cohort studies. Schizophr Bull 2012; 38: 661-671.

7. Bechdolf A, Thompson A, Nelson B, Cotton S, Simmons MB, Amminger GP, et al. Experience of trauma and conversion to psychosis in an ultra-high-risk (prodromal) group. Acta Psychiatr Scand 2010; 121: 377-384.

8. Conus P, Cotton S, Schimmelmann BG, McGorry PD, Lambert M. Pretreatment and outcome correlates of sexual and physical trauma in an epidemiological cohort of first-episode psychosis patients. Schizophr Bull 2010; 36: 1105-1114.

9. Morgan C, Fisher H. Environment and schizophrenia: environmental factors in schizophrenia: childhood traumaa critical review. Schizophr Bull 2007; 33: 3-10.

10. Schäfer I, Fisher HL. Childhood trauma and psychosis - what is the evidence? Dialogues Clin Neurosci 2011; 13: 360-365.

11. Thompson AD, Nelson B, Yuen HP, Lin A, Amminger GP, McGorry PD, et al. Sexual trauma increases the risk of developing psychosis in an ultra high-risk "prodromal“" population. Schizophr Bull 2013 Mar 2. [Epub ahead of print]. doi: 10.1093/schbul/sbt032.

12. Uçok A, Bikmaz S. The effects of childhood trauma in patients with first-episode schizophrenia. Acta Psychiatr Scand 2007; 116: 371-377.

13. Janssen I, Krabbendam L, Bak M, Hanssen M, Vollebergh W, de Graaf R, et al. Childhood abuse as a risk factor for psychotic experiences. Acta Psychiatr Scand 2004; 109: $38-45$.
14. Spauwen J, Krabbendam L, Lieb R, Wittchen HU, van Os J. Impact of psychological trauma on the development of psychotic symptoms: relationship with psychosis proneness. Br J Psychiatry 2006; 188: 527-533.

15. Kilcommons AM, Morrison AP, Knight A, Lobban F. Psychotic experiences in people who have been sexually assaulted. Soc Psychiatry Psychiatr Epidemiol 2008; 43: 602-611.

16. Read J, Agar K, Argyle N, Aderhold V. Sexual and physical abuse during childhood and adulthood as predictors of hallucinations, delusions and thought disorder. Psychol Psychother 2003; 76: 1-22.

17. Read J, van Os J, Morrison AP, Ross CA. Childhood trauma, psychosis and schizophrenia: a literature review with theoretical and clinical implications. Acta Psychiatr Scand 2005; 112: 330-350.

18. Shevlin M, Dorahy MJ, Adamson G. Childhood traumas and hallucinations: an analysis of the National Comorbidity Survey. J Psychiatr Res 2007; 41: 222-228.

19. Shevlin M, Murphy J, Read J, Mallett J, Adamson G, Houston JE. Childhood adversity and hallucinations: a community-based study using the National Comorbidity Survey Replication. Soc Psychiatry Psychiatr Epidemiol 2011; 46: 1203-1210.

20. Perona S, García JM, Cuevas C, Perez M, Ductor MJ, Salas R, et al. A preliminary exploration of trauma, dissociation, and positive psychotic symptoms in a Spanish sample. J Trauma Dissociation 2010; 11: 284-292.

21. Whitfield CL, Dube SR, Felitti VJ, Anda RF. Adverse childhood experiences and hallucinations. Child Abuse Negl 2005; 29: 797-810.

22. Freeman D, Fowler D. Routes to psychotic symptoms: trauma, anxiety and psychosis-like experiences. Psychiatry Res 2009; 169: 107-112.

23. Kilcommons AM, Morrison AP. Relationships between trauma and psychosis: an exploration of cognitive and dissociative factors. Acta Psychiatr Scand 2005; 112: 351-359.

24. McCarthy-Jones S. Voices from the storm: a critical review of quantitative studies of auditory verbal hallucinations and childhood sexual abuse. Clin Psychol Rev 2011; 31: 983-992.

25. Heins M, Simons C, Lataster T, Pfeifer S, Versmissen D, Lardinois M, et al. Childhood trauma and psychosis: a case-control and case-sibling comparison across different levels of genetic liability, psychopathology, and type of trauma. Am J Psychiatry 2011; 168: 1286-1294.

26. Larkin W, Read J. Childhood trauma and psychosis: evidence, pathways, and implications. J Postgrad Med 2008; 54: 287-293. 
27. Morrison AP. A cognitive behavioural perspective on the relationship between childhood trauma and psychosis. Epidemiol Psichiatr Soc 2009; 18: 294-298.

28. Scott J, Chant D, Andrews G, Martin G, McGrath J. Association between trauma exposure and delusional experiences in a large community-based sample. Br J Psychiatry 2007; 190: 339-343.

29. Shevlin M, Dorahy MJ, Adamson G. Trauma and psychosis: an analysis of the National Comorbidity Survey. Am J Psychiatry 2007; 164: 166-169.

30. Shevlin M, Houston JE, Dorahy MJ, Adamson G. Cumulative traumas and psychosis: an analysis of the national comorbidity survey and the British Psychiatric Morbidity Survey. Schizophr Bull 2008; 34: 193-199.

31. Schreier A, Wolke D, Thomas K, Horwood J, Hollis C, Gunnell D, et al. Prospective study of peer victimization in childhood and psychotic symptoms in a nonclinical population at age 12 years. Arch Gen Psychiatry 2009; 66: 527-536.

32. Fisher H, Jones P, Fearon P, Morgan K, Dazzan P, Lappin $\mathrm{J}$, et al. The varying impact of type, timing and frequency of exposure to childhood adversity on its association with adult psychotic disorder. Psychol Med 2010; 40: 1967-1978.

33. Fisher H, Morgan C, Dazzan P, Kirkbride J, Craig TK, Morgan $\mathrm{K}$, et al. Gender differences in the association between childhood abuse and psychosis. Br J Psychiatry 2009; 194: 319-325.

34. Kramer IM, Simons CJ, Myin-Germeys I, Jacobs N, Derom C, Thiery E, et al. Evidence that genes for depression impact on the pathway from trauma to psychotic-like symptoms by occasioning emotional dysregulation. Psychol Med 2011; 11: 1-12.

35. Harley M, Kellehar I, Clarke M, Lynch F, Arseneault L, Connor D, et al. Cannabis use and childhood trauma interact additively to increase the risk of psychotic symptoms in adolescence. Psychol Med 2010; 40: 1627-1634.

36. Houston JE, Murphy J, Adamson G, Stringer M, Shevlin M. Childhood sexual abuse, early cannabis use, and psychosis: testing an interaction model based on the National Comorbidity Survey. Schizophr Bull 2008; 34: 580-585.

37. Lovatt A, Mason O, Brett C, Peters E. Psychotic-like experiences, appraisals, and trauma. J Nerv Ment Dis 2010; 198: 813-819.

38. Gracie A, Freeman D, Green S, Garety PA, Kuipers $\mathrm{E}$, Hardy A, et al. The association between traumatic experience, paranoia and hallucinations: a test of the predictions of psychological models. Acta Psychiatr Scand 2007; 116: 280-289.

39. Longden E, Madill A, Waterman MG. Dissociation, trauma, and the role of lived experience: toward a new conceptualization of voice hearing. Schizophr Bull 2012; 138: $28-76$
40. Perona S, Carrascoso F, García JM, Ductor MJ, López AM, Vallina $\mathrm{O}$, et al. Dissociative experiences as mediators between childhood trauma and auditory hallucinations. J Trauma Stress 2012; 25: 323-329.

41. Varese F, Barkus E, Bentall RP. Dissociation mediates the relationship between childhood trauma and hallucination-proneness. Psychol Med 2012; 42: 1025-1036.

42. Bebbington P, Jonas S, Kuipers E, King M, Cooper C, Brugha T, et al. Childhood sexual abuse and psychosis: data from a cross-sectional national psychiatric survey in England. Br J Psychiatry 2011; 199: 29-37.

43. Lysaker PH, Salyers MP. Anxiety symptoms in schizophrenia spectrum disorders: associations with social function, positive and negative symptoms, hope and trauma history. Acta Psychiatr Scand 2007; 116: 290-298.

44. Tibbo P, Swainson J, Chue P, LeMelledo JM. Prevalence and relationship to delusions and hallucinations of anxiety disorders in schizophrenia. Depress Anxiety 2003; 17: 65-72.

45. Collip D, Myin-Germeys I, Wichers M, Jacobs N, Derom C, Thiery E, et al. FKBP5 as a possible moderator of the psychosis-inducing effects of childhood trauma. Br J Psychiatry 2013; 202: 261-268.

46. Lardinois M, Lataster T, Mengelers R, Van Os J, MyinGermeys I. Childhood trauma and increased stress sensitivity in psychosis. Acta Psychiatr Scand 2011; 123: 28-35.

47. Read J, Perry BD, Moskowitz A, Connolly J. The contribution of early traumatic events to schizophrenia in some patients: A traumagenic neurodevelopmental model. Psychiatry $2001 ; 64: 319-345$.

48. Hoy K, Barrett S, Shannon C, Campbell C, Watson D, Rushe $\mathrm{T}$, et al. Childhood trauma and hippocampal and amygdalar volumes in first-episode psychosis. Schizophr Bull 2012; 38: 1162-1169.

49. Beards S, Gayer-Anderson C, Borges S, Dewey ME, Fisher HL, Morgan C. Life events and psychosis: a review and meta-analysis. Schizophr Bull 2013; 39: 740-747.

50. Raune D, Kuipers E, Bebbington P. Stressful and intrusive life events preceding first episode psychosis. Epidemiol Psichiatr Soc 2009; 18: 221-228.

51. World Health Organization. The ICD-10 Classification of Mental and Behavioural Disorders: Clinical Descriptions and Diagnostic Guidelines. Geneva: World Health Organization; 1992.

52. American Psychiatric Association. Diagnostic and statistical manual of mental disorders: DSM-IV-TR. Washington, DC: American Psychiatric Association; 2000.

53. American Psychiatric Association. Diagnostic and statistical manual of mental disorders (3rd ed, rev). Washington, DC: American Psychiatric Association; 1987. 
54. Hlastala SA, McClellan J. Phenomenology and diagnostic stability of youths with atypical psychotic symptoms. J Child Adolesc Psychopharmacol 2005; 15: 497-509.

55. Marneros A, Pillmann F, Haring A, Balzuweit S. Acute and transient psychotic disorders. Fortschr Neurol Psychiatr 2000; 68: 22-25.

56. Salem M, Moselhy H, Attia H, Yousef S. Psychogenic psychosis revisited: A follow up study. Int J Health Sci 2009; 3: 45-49.

57. Janet P. Névroses et idées fixes, Vol. 1. Paris: Félix Alcan; 1898.

58. Breuer J. Theoretical. In: Strachey J (Transl. and Ed.). The standard Edition of the Complete Psychological Works of Sigmund Freud, Vol. 3. London: Hogarth Press; 1955. p. 259-333.

59. Jablensky A. Classification of nonschizophrenic psychotic disorders: a historical perspective. Curr Psychiatry Rep 2001; 3: 326-331.

60. Modestin J, Bachmann KM. Is the diagnosis of hysterical psychosis justified? Clinical study of hysterical psychosis, reactive/psychogenic psychosis, and schizophrenia. Compr Psychiatry 1992; 33: 17-24.

61. Modestin J, Sonderegger P, Erni T. Follow-up study of hysterical psychosis, reactive/psychogenic psychosis, and schizophrenia. Compr Psychiatry 2001; 42: 51-56.

62. Castagnini AC. Wimmer's concept of psychogenic psychosis revisited. Hist Psychiatry 2010; 21: 54-66.

63. Formoso SM, Romero MA. Psychogenic psychosis. Actas Esp Psiquiatr 2007; 35: 219-220.

64. Hollender MH, Hirsch SJ. Hysterical psychosis. Am J Psychiatry 1964; 120: 1066-1074.

65. Chinchilla A, López-Ibor JJ, Cebollada A, Carrasco JL, Vega M, Jordá L, et al. Hysterical psychosis: clinical aspects and disease course. Actas Esp Psiquiatr 1989; 17: 231-236.

66. Der Hart OV, Witztum E, Friedman B. From hysterical psychosis to reactive dissociative psychosis. J Trauma Stress 1993; 6: 1-13.

67. Gift TE, Strauss JS, Young Y. Hysterical psychosis: an empirical approach. Am J Psychiatry 1985; 142: 345-347.

68. Nava AS. Hysterical psychoses revisited. Acta Med Port 1995; 8: 705-709.

69. Bessoles P. Post-traumatic psychosis: the contribution of an acute post-immediate trauma to a dynamic theorization. Encephale 2006; 32: 729-737.

70. Seedat S, Stein MB, Oosthuizen PP, Emsley RA, Stein DJ. Linking posttraumatic stress disorder and psychosis: a look at epidemiology, phenomenology, and treatment. J Nerv Ment Dis 2003; 191: 675-681.
71. Calhoun PS, Stechuchak KM, Strauss J, Bosworth HB, Marx CE, Butterfield MI. Interpersonal trauma, war zone exposure, and posttraumatic stress disorder among veterans with schizophrenia. Schizophr Res 2007; 91: 210-216.

72. Fan X, Henderson DC, Nguyen DD, Cather C, Freudenreich O, Evins AE, et al. Posttraumatic stress disorder, cognitive function and quality of life in patients with schizophrenia. Psychiatry Res 2008; 159: 140-146.

73. Schäfer I, Fisher HL. Childhood trauma and posttraumatic stress disorder in patients with psychosis: clinical challenges and emerging treatments. Curr Opin Psychiatry 2011; 24: 514-518.

74. Strauss JL, Calhoun PS, Marx CE, Stechuchak KM, Oddone EZ, Swartz MS, et al. Comorbid posttraumatic stress disorder is associated with suicidality in male veterans with schizophrenia or schizoaffective disorder. Schizophr Res 2006; 84: 165-169.

75. Kessler RC, Chiu WT, Demler O, Merikangas KR, Walters EE. Prevalence, severity, and comorbidity of 12month DSM-IV disorders in the National Comorbidity Survey Replication. Arch Gen Psychiatry 2005; 62: 617-627.

76. Gaudiano BA, Zimmerman M. Evaluation of evidence for the psychotic subtyping of post-traumatic stress disorder. Br J Psychiatry 2010; 197: 326-327.

77. Kastelan A, Franciskovi T, Moro L, Roncević GI, Grković J, Jurcan V, et al. Psychotic symptoms in combatrelated post-traumatic stress disorder. Mil Med 2007; 172: 273-277.

78. Kozarić-Kovacić D, Borovecki A. Prevalence of psychotic comorbidity in combat-related post-traumatic stress disorder. Mil Med 2005; 170: 223-226.

79. Campbell ML, Morrison AP. The psychological consequences of combat exposure: the importance of appraisals and post-traumatic stress disorder symptomatology in the occurrence of delusional-like ideas. Br J Clin Psychol 2007; 46: 187-201.

80. Sareen J, Cox BJ, Goodwin RD, Asmundson GJ. Co-occurrence of posttraumatic stress disorder with positive psychotic symptoms in a nationally representative sample. J Trauma Stress 2005; 18: 313-322.

81. Auxéméry Y, Fidelle G. Psychosis and trauma. Theorical links between post-traumatic and psychotic symptoms. Encephale 2011; 37: 433-438.

82. Berry K, Ford S, Jellicoe-Jones L, Haddock G. PTSD symptoms associated with the experiences of psychosis and hospitalisation: A review of the literature. Clin Psychol Rev 2013; 33: 526-538.

83. Chisholm B, Freeman D, Cooke A. Identifying potential predictors of traumatic reactions to psychotic episodes. Br J Clin Psychol 2006; 45: 545-559. 
84. Jackson C, Knott C, Skeate A, Birchwood M. The trauma of first episode psychosis: the role of cognitive mediation. Aust N Z J Psychiatry 2004; 38: 327-333.

85. Lu W, Mueser KT, Shami A, Siglag M, Petrides G, Schoepp E, et al. Post-traumatic reactions to psychosis in people with multiple psychotic episodes. Schizophr Res 2011; 127: 66-75.

86. Mueser KT, Lu W, Rosenberg SD, Wolfe R. The trauma of psychosis: posttraumatic stress disorder and recent onset psychosis. Schizophr Res 2010; 116: 217-227.

87. Tarrier N, Khan S, Cater J, Picken A. The subjective consequences of suffering a first episode psychosis: trauma and suicide behaviour. Soc Psychiatry Psychiatr Epidemiol 2007; 42: 29-35.

88. White RG, Gumley AI. Postpsychotic posttraumatic stress disorder: associations with fear of recurrence and intolerance of uncertainty. J Nerv Ment Dis 2009; 197: 841-849.

89. Beattie N, Shannon C, Kavanagh M, Mulholland C. Predictors of PTSD symptoms in response to psychosis and psychiatric admission. J Nerv Ment Dis 2009; 197: 56-60.

90. Bendall S, Alvarez-Jimenez M, Hulbert CA, McGorry PD, Jackson HJ. Childhood trauma increases the risk of post-traumatic stress disorder in response to first-episode psychosis. Aust N Z J Psychiatry 2012; 46: 35-39.

91. Morrison AP, Frame L, Larkin W. Relationships between trauma and psychosis: A review and integration. Br J Clin Psychol 2003; 42: 331-353.

92. Bosson JV, Reuther ET, Cohen AS. The comorbidity of psychotic symptoms and posttraumatic stress disorder: evidence for a specifier in DSM-5. Clin Schizophr Relat Psychoses 2011; 5: 147-154.

93. Kurth RA, Gerhardt H, Schäfer I. Post-traumatic and psychotic symptoms in severely traumatized patients. Fortschr Neurol Psychiatr 2012; 80: 24-28.

94. Pivac N, Kozaric-Kovacic D, Mustapic M, Dezeljin M, Borovecki A, Grubisic-Ilic M, et al. Platelet serotonin in combat related posttraumatic stress disorder with psychotic symptoms. J Affect Disord 2006; 93: 223-227.

95. Sautter FJ, Bissette G, Wiley J, Manguno-Mire G, Schoenbachler B, Myers L, et al. Corticotropin-releasing factor in posttraumatic stress disorder (PTSD) with secondary psychotic symptoms, nonpsychotic PTSD, and healthy control subjects. Biol Psychiatry 2003; 54: 1382-1388.

96. Hamner MB, Gold PB. Plasma dopamine beta-hydroxylase activity in psychotic and non-psychotic post-traumatic stress disorder. Psychiatry Res 1998; 77: 175-181.

97. Cerbone A, Sautter FJ, Manguno-Mire G, Evans WE, Tomlin H, Schwartz B, et al. Differences in smooth pursuit eye movement between posttraumatic stress disorder with secondary psychotic symptoms and schizophrenia. Schizophr Res 2003; 63: 59-62.

98. Pivac N, Kozaric-Kovacic D, Grubisic-Ilic M, Nedic G, Rakos I, Nikolac M, et al. The association between brainderived neurotrophic factor Val66Met variants and psychotic symptoms in posttraumatic stress disorder. World $\mathrm{J}$ Biol Psychiatry 2012; 13: 306-311.

99. Kozarić-Kovacić D, Pivac N, Mück-Seler D, Rothbaum BO. Risperidone in psychotic combat-related posttraumatic stress disorder: an open trial. J Clin Psychiatry 2005; 66: 922-927.

100. Kozaric-Kovacic D, Pivac N. Quetiapine treatment in an open trial in combat-related post-traumatic stress disorder with psychotic features. Int J Neuropsychopharmacol 2007; 10: 253-261.

101. Pivac N, Kozarić-Kovacić D. Pharmacotherapy of treatment-resistant combat-related posttraumatic stress disorder with psychotic features. Croat Med J 2006; 47: 440-451.

102. Shevlin M, Armour C, Murphy J, Houston JE, Adamson G. Evidence for a psychotic posttraumatic stress disorder subtype based on the National Comorbidity Survey. Soc Psychiatry Psychiatr Epidemiol 2011; 46: 1069-1078.

103. Braakman MH, Kortmann FA, van den Brink W, Verkes RJ. Posttraumatic stress disorder with secondary psychotic features: neurobiological findings. Prog Brain Res 2008; 167: 299-302.

104. Braakman MH, Kortmann FA, van den Brink W. Validity of 'post-traumatic stress disorder with secondary psychotic features': a review of the evidence. Acta Psychiatr Scand 2009; 119: 15-24.

105. Hardy A, Fowler D, Freeman D, Smith B, Steel C, Evans J, et al. Trauma and hallucinatory experience in psychosis. J Nerv Ment Dis 2005; 193: 501-517.

106. Thompson A, Nelson B, McNab C, Simmons M, Leicester S, McGorry PD, et al. Psychotic symptoms with sexual content in the "ultra high risk" for psychosis population: frequency and association with sexual trauma. Psychiatry Res 2010; 177: 84-91.

107. Frueh BC, Grubaugh AL, Cusack KJ, Kimble MO, Elhai JD, Knapp RG. Exposure-based cognitive-behavioral treatment of PTSD in adults with schizophrenia or schizoaffective disorder: a pilot study. J Anxiety Disord 2009; 23: 665-675.

108. Long ME, Grubaugh AL, Elhai JD, Cusack KJ, Knapp R, Frueh BC. Therapist fidelity with an exposurebased treatment of PTSD in adults with schizophrenia or schizoaffective disorder. J Clin Psychol 2010; 66: 383-393. 
109. van den Berg M, Hendriks GJ, van Minnen A. Imaginal exposure treatment for a post-traumatic stress disorder in a patient with a comorbid psychotic disorder. Tijdschr Psychiatr 2010; 52: 191-195.

110. van den Berg DP, van der Gaag M. Treating trauma in psychosis with EMDR: a pilot study. J Behav Ther Exp Psychiatry 2012; 43: 664-671.

111. van der Vleugel BM, van den Berg DP, Staring AB. Trauma, psychosis, post-traumatic stress disorder and the application of EMDR. Riv Psichiatr 2012; 47: 33-38.

112. Jackson C, Trower P, Reid I, Smith J, Hall M, Townend $\mathrm{M}$, et al. Improving psychological adjustment following a first episode of psychosis: a randomised controlled trial of cognitive therapy to reduce post psychotic trauma symptoms. Behav Res Ther 2009; 47: 454-462.

113. Jackson C, Bernard M, Birchwood M. The efficacy of psychotherapy in reducing post-psychotic trauma. Epidemiol Psychiatr Sci 2011; 20: 127-131.

Corresponding author:

Álvaro Frías Ibáñez

Servicio de Psiquiatría. Hospital de Mataró

Ctra. Cirera s/n CP: 08304 Mataró (Barcelona)

Phone number: +34 937417700 (ext. 4701)

E-mail address: afrias@csdm.cat 